\title{
Perancangan Sistem Jaminan Halal (SJH) pada IKM Roti Amira untuk Memenuhi Persyaratan Dokumentasi Sistem Jaminan Halal (SJH)
}

\author{
Muhammad Abiyyu Arsyan*), Eko Liquiddanu dan Eko Pujiyanto \\ Program Studi Teknik Industri, Fakultas Teknik, Universitas Sebelas Maret \\ Jl. Ir. Sutami 36 A Kentingan, Surakarta, 57126, Indonesia
}

DOI: 10.20961/performa.18.1.29218

\begin{abstract}
Abstrak
IKM Roti Amira merupakan salah satu IKM yang memproduksi roti di Kota Surakarta. IKM ini sudah memiliki PIRT tetapi belum memiliki sertifikat halal. Pada akhir tahun 2019 semua industri makanan dan minuman harus memiliki serifikat halal sebagaimana pada amanat UU Nomor 33 Tahun 2014 Pasal 4. Jika tidak produk Roti Amira dapat di tarik dari peredaran oleh pemerintah. Oleh karena itu perlu dilakukan pendaftaran sertifikat halal dengan merancang sistem jaminan halal (SJH). Tujuan penelitian ini adalah merancang sistem jaminan halal pada proses bisnis dan proses produksi sebagai persyaratan mendapatkan sertifikat halal pada Roti Amira. Serta melengkapi dokumen proses produksi halal dan dokumen SJH untuk mengajukan persyaratan halal MUI. Manfaat penelitian ini adalah untuk membantu Roti Amira dalam memperbaiki proses bisnis, proses produksi dan SOP yang sesuai dengan standar halal pada Roti Amira serta menyiapkan persyaratan administrasi (dokumentasi) sertifikat halal dari LPPOM MUI. Penelitian ini berisi perbaikan proses bisnis, yaitu: struktur organisasi dan model value chain Porter untuk mengetahui aliran material dari pembelian bahan baku sampai produk jadi yang didistribusikan ke konsumen. Kemudian membuat OPC serta perbaikannnya yang mengetahui lebih detail setiap aktivitas perusahaan. Setelah itu menyusun SOP halal Roti Amira. Kesimpulan penelitian ini yaitu Roti Amira akan menerapkan SJH dengan perbaikan pada proses bisnis, proses produksi dan SOP halal. Sehingga hasil dari penelitian ini perbaikan proses bisnis, proses produksi, dan SOP halal yang sesuai dengan standar SJH.
\end{abstract}

Kata kunci: SJH, HAS, OPC, titik kritis, value chain porter.

\begin{abstract}
Roti Amira SME is one of the SME that produce bread in Surakarta City. This SME already has a PIRT but does not have a halal certificate. At the end of 2019 all food and beverage industries must have halal certificates as mandated by Law Number 33 Year 2014 Article 4. If not Roti Amira products can be withdrawn from circulation by the government. Therefore it is necessary to register halal certificates consisting of technical requirements and documentation requirements. The purpose of this study was to design a halal guarantee system in business processes and production processes as a requirement to obtain a halal certificate on Roti Amira. And complete the halal's production process documents and HAS documents to propose MUI's halal certificate. The benefits of this research are to help Roti Amira in improving business processes, production processes and SOP that are in accordance with halal standards on Amira Roti and preparing administrative requirements (documentation) of halal certificates from LPPOM MUI. This research contains improvement of business processes, namely: organizational structure and Porter's value chain model to determine the flow of material from the purchase of raw materials to finished products that are distributed to consumers. Then make $O P C$ and its improvements to know more in detail about each company activity and blind the critical points in each process. After that, compiled the halal SOP in Roti Amira. The conclusion of this study is that Roti Amira will implement SJH with improvements to business processes, production processes and halal SOP. So that the results of this study improve business processes, production processes, and halal SOP that are in accordance with HAS standards.
\end{abstract}

Keywords: SJH, HAS, OPC, critical point, value chain porter

\section{Pendahuluan}

Subsektor industri makanan dan minuman memiliki persen kontribusi PDRB terbesar dibandingkan keenambelas subsektor industri lainnya yang berada di kota Surakarta. Dengan rata-rata persentase sebesar 32,1\% terhadap total nilai tambah sektor industri dimulai dari tahun 2011 sampai dengan tahun 2016. Besarnya PDRB industri makanan dan minuman menunjukkan dominan terhadap kontribusi industri secara keseluruhan. Sektor industri makanan dan minuman saat ini dihadapkan pada masalah sertifikasi halal yang belum diadopsi oleh

"Korespondensi : abiyyuarsyan95@gmail.com 
seluruh industri di Kota Surakarta, salah satunya adalah produk olahan roti. Masyarakat yang tinggal di kotakota besar lebih memilih roti sebagai makanan pokok pendamping dikarenakan roti memiliki kandungan gizi yang lebih tinggi dan lengkap dibandingkan makanan pokok pendamping lainnya, sehingga dapat menggantikan fungsi nasi sebagai sumber karbohidrat utama (Octaviani, 2012).

Sesuai dengan amanat Undang-Undang Republik Indonesia Nomor 33 Tahun 2014 tentang Jaminan Produk Halal Pasal 4 menyebutkan bahwa produk yang masuk, beredar, dan diperdagangkan di wilayah Indonesia wajib bersertifikat halal. Produk halal yang dimaksud mencakup penyediaan bahan, pengolahan, penyimpanan, pengemasan, pendistribusian, penjualan, dan penyajian produk. Pasal 67 Ayat 1 menyebutkan bahwa kewajiban bersertifikat halal bagi produk yang beredar dan diperdagangkan di wilayah Indonesia sebagaimana dimaksud dalam Pasal 4 mulai berlaku 5 (lima) tahun terhitung sejak undang-undang ini diundangkan pada tanggal 17 Oktober 2014. Oleh karena itu semua produk wajib untuk bersertifikat halal mulai tanggal 17 Oktober 2019 sesuai dengan amanat UU No. 33 Tahun 2014 tentang Jaminan Produk Halal (UU No. $33,2014)$. Semua IKM makanan dan minuman harus memiliki sertifikasi halal untuk bisa menjual produk ke seluruh wilayah di Indonesia. Jika tidak memiliki sertifikasi halal, maka produk olahan makanan dan minuman bisa ditarik dari peredaran oleh pemerintah.

Salah satu industri makanan di Kota Surakarta adalah IKM Roti Amira yang berlokasi di Jalan Bogowoto No.58, Semanggi, Ps. Kliwon, Kota Surakarta, Jawa Tengah. Saat ini IKM Roti Amira sudah memiliki PIRT dengan nomor 20633720426, namun belum memiliki sertifikat halal dari MUI Jawa Tengah. Kondisi ini menjadi hambatan bagi IKM Roti Amira karena menurut peraturan undang-undang sejak Oktober 2019 tidak bisa menjual lagi produk rotinya di kota Surakarta maupun di seluruh Indonesia.

Syarat untuk mendapatkan sertifikasi halal dibagi menjadi dua, yaitu syarat administrasi (dokumentasi) dan syarat teknis. Pihak Roti Amira sudah menyiapkan persyaratan secara teknis tetapi syarat administrasi masih belum dilakukan. Sehingga pihak manajemen perlu menyiapkan draft dokumen sistem jaminan halal (SJH) sebagai syarat administrasi untuk mendapatkan sertifikasi halal dari MUI. Draft dokumen sistem jaminan halal (SJH) harus sesuai dengan HAS 23000. HAS 23000 adalah dokumen yang berisi persyaratan sertifikasi halal LPPOM MUI (LPPOM MUI, 2008). Draft dokumen ini berisi dokumen sistem jaminan halal berupa: kebijakan halal, tim manajemen halal, pelatihan dan edukasi, dokumentasi bahan, dokumentasi produk, dokumentasi fasilitas produksi, prosedur tertulis aktivitas tertulis, dokumentasi kemampuan telusur, prosedur penanganan produk yang tidak memenuhi kriteria, dokumentasi audit internal, dan dokumentasi kaji ulang manajemen. Dari penjelasan diatas maka, penelitian ini membantu dalam menyiapkan SJH bagi Roti Amira agar mendapatkan sertifikat halal. Tujuan dari penelitian ini yaitu: Merancang sistem jaminan halal pada proses bisnis dan proses produksi sebagai persyaratan mendapatkan sertifikat halal pada IKM Roti Amira. Dan melengkapi dokumen proses produksi halal dan dokumen SJH untuk mengajukan persyaratan halal MUI. Manfaat dari penelitian ini adalah untuk membantu Roti Amira dalam memperbaiki proses bisnis, proses produksi dan SOP yang sesuai dengan standar halal pada Roti Amira serta menyiapkan persyaratan administrasi (dokumentasi) sertifikat halal dari LPPOM MUI.

\section{Metode Penelitian}

Penelitian ini diawali dengan studi lapangan studi literatur dan lapangan untuk mengidentifikasi permasalahan yang terjadi pada Roti Amira. Berdasarkan identifikasi masalah yang telah dilakukan tersebut kemudian digunakan untuk menyusun rumusan masalah dan tujuan masalah. Tahap selanjutnya yaitu tahap pengumpulan dan pengolahan data. Pengumpulan data dibagi menjadi beberapa tahapan, yaitu:

\subsection{Pengumpulan Data}

Subbab ini menjelaskan mengenai menjelaskan bagaimana pengumpulan data berdasarkan tahapan penelitian yang telah disusun. Pada tahap ini dilakukan pengumpulan data yang diperlukan untuk menyusun dokumen proses produksi halal sebagai pemantauan pada setiap aktivitas perusahaan. Pengumpulan data dibagi menjadi tiga tahap, yaitu:

A. Tahap wawancara

Tahap ini dilakukan dengan wawancara atau dengan melakukan tanya jawab langsung oleh owner/ manajer Roti Amira. Topik-topik yang diwawancarai adalah mengenai sistem produksi halal secara keseluruhan mulai dari pembelian bahan sampai ke distribusi produk ke konsumen.

B. Tahap perekaman

Tahap ini dilakukan untuk memfoto dan merekam aktivitas produksi serta bahan baku yang digunakan dengan meminta izin terlebih dahulu oleh owner Roti Amira. 
C. Tahap dokumentasi

Tahap ini merupakan meminta izin kepada owner/ manajer Roti Amira untuk mendapatkan dokumendokumen perusahaan yang akan digunakan sebagai data pendukung dalam pembuatan dokumen proses produksi halal.

\subsection{Perancangan Sistem Jaminan Halal (SJH) dengan Memperbaiki Proses Produksi Halal}

Perancangan SJH dibagi menjadi tiga yaitu perancangan proses produksi halal untuk mengetahui langkahlangkah teknis didalam SJH yang digunakan untuk pemantauan oleh MUI (Denny, W., 2018). Ketiga tahapan tersebut adalah sebagai berikut:

1. Identifikasi proses bisnis beserta perbaikan

2. Identifikasi proses produksi beserta perbaikan

3. Menyusun standard operations procedure (SOP) halal dari perbaikan OPC

\section{Identifikasi Proses Bisnis Beserta Perbaikan}

Proses bisnis merupakan kumpulan aktivitas yang membutuhkan satu atau lebih inputan dan menghasilkan output yang bermanfaat/ bernilai bagi pelanggan. Dalam penelitian ini identifikasi proses bisnis menggunakan model value chain Porter. Model value chain Porter digunakan untuk mengetahui aliran material dan proses bisnis dari pembelian bahan sampai dengan distribusi produk ke konsumen yang terdiri aktivitas primer dan aktivitas sekunder. Berikut alur proses bisnis sesuai dengan model value chain Porter:

a. Melakukan pemantauan langsung ke lokasi aktivitas.

b. Melihat standar SJH MUI.

c. Penyesuian proses yang ada dengan standar SJH MUI.

d. Melakukan perbaikan jika tidak sesuai dengan standar SJH MUI.

Pada keempat tahapan di atas dilakukan juga untuk semua aktivitas primer mulai dari inbound logistics, operations, outbound logistics sampai dengan marketing and sales.

\subsection{Identifikasi Proses Produksi Beserta Perbaikan}

Setelah menguraikan proses bisnis langkah selanjutnya diuraikan menjadi beberapa proses dengan menggunakan metode OPC. OPC digunakan untuk mengetahui secara detail aktivitas dari masing-masing stasiun kerja. Berikut langkah-langkah penyusunan OPC beserta perbaikannya:

a. Menyusun proses produksi saat ini dengan menggunakan OPC.

b. Melakukan perbaikan OPC dengan menyesuaikan standar halal MUI.

Pada tahap selanjutnya OPC dijadikan acuan untuk menyusun standar operasi prosedur halal (SOP halal).

\subsection{Menyusun Standard Operation Procedure (SOP) Halal dari Perbaikan OPC}

Penyusunan SOP halal mengacu dari OPC yang telah disusun. Langkah-langkah pembuatan SOP halal adalah sebagai berikut:
a. Penyusunan tujuan prosedur
b. Penyusunan ruang lingkup prosedur
c. Penulisan referensi prosedur yang menjadi acuan
d. Menguraikan aktivitas proses
e. Membuat flowchart proses
f. Identifikasi dokumen yang dihasilkan

\subsection{Membuat Matriks Hubungan Antara Dokumen Proses Produksi Halal dengan Dokumen Pendaftaran SJH MUI}

Penyusunan matriks hubungan antara dokumen proses produksi halal dengan dokumen pendaftaran SJH MUI yang mengacu dari OPC yang telah disusun. Langkah-langkah pembuatan matriks hubungan adalah sebagai berikut:

a. Menguraikan dokumen-dokumen proses halal.

b. Menguraikan dokumen-dokumen pendaftaran SJH MUI.

c. Mengaitkan proses halal dengan proses dokumen pendaftaran SJH MUI.

\section{Hasil dan Pembahasan}

Hasil yang diperoleh dari penelitian meliputi kesesuaian kondisi real Roti Amira dengan dokumen SJH, model value chain Porter, OPC dari aktivtas masing-masing divisi dan titik kritis setiap proses. 


\subsection{Proses Bisnis di Roti Amira}

\section{A. Perbaikan Struktur Organisasi Roti Amira}

Pada struktur organisasi Roti Amira harus sesuai dengan standar SJH yang dikeluarkan oleh LPPOM MUI. Terdapat beberapa perbaikan struktur organisasi beserta tugasnya untuk bisa menerapkan SJH, yaitu sebagai berikut:

1. Harus adanya bagian pengendalian dan pengawasan mutu (Quality Assurancel Quality Control). Bagian ini harus berdiri sendiri dan tidak bercampur pada bagian produksi dan bagian pembelian. Jika tidak, maka ada konflik internal serta pada bagian pembelian dan bagian produksi akan terjadi kecurangan karena melakukan pemeriksaan dan pekerjaan secara bersamaan. Karena audit internal memiliki tugas yang sama dengan bagian QA/ QC maka bagian tersebut digabung sehubungan dengan keterbatasan jumlah anggota di Roti Amira. Berikut tugas bagian QA/ QC adalah sebagai berikut:

a. Menyusun dan melaksanakan prosedur pemantauan dan pengendalian untuk menjamin konsistensi produksi halal.

b. Melaksanakan pemeriksaan terhadap setiap bahan yang masuk sesuai dengan sertifikat halal, spesifikasi dan produsennya.

c. Melakukan pemantauan terhadap setiap penyimpangan dan ketidakcocokan bahan dengan dokumen kehalalan.

2. Bagian produk harus berdiri sendiri karena hanya bertanggung jawab atas semua proses produksi. Pada perbaikan bagian produk terdapat beberapa perbaikan adalah sebagai berikut:

a. Menyusun prosedur produksi yang dapat menjamin kehalalan produk.

b. Melakukan pemantauan produksi yang bersih dan bebas dari bahan haram dan najis.

c. Menjalankan kegiatan produksi sesuai dengan matriks formulasi bahan yang telah disusun oleh auditor internal dan diketahui oleh LPPOM MUI.

d. Melakukan komunikasi dengan bagian QC/ auditor internal dalam hal proses produksi halal.

3. Bagian pembelian, bagian pergudangan dan bagian PPIC digabung menjadi bagian pembelian karena perusahaan ini masih yang keterbatasan jumlah anggota dan bagian tersebut bertanggung jawab pada aktivitas inbound logistics. Bagian ini memiliki beberapa tugas antara lain sebagai berikut:

a. Menyusun prosedur administrasi pergudangan yang dapat menjamin kehalalan bahan dan produk yang disimpan serta menghindari terjadinya kontaminasi dari segala sesuatu yang haram dan najis.

b. Melaksanakan penyimpanan produk dan bahan sesuai dengan daftar bahan dan produk yang telah disusun oleh auditor internal dan diketahui oleh LPPOM MUI.

c. Melakukan komunikasi dengan bagian QC/ auditor internal dalam sistem keluar masuknya bahan dari dan ke dalam gudang serta pembelian bahan baru dan atau pemilihan pemasok baru.

d. Menyusun prosedur dan melaksanakan pembelian yang dapat menjamin konsistensi bahan sesuai dengan daftar bahan yang telah disusun oleh auditor internal dan diketahui oleh LPPOM MUI.

e. Melakukan evaluasi terhadap pemasok dan menyusun peringkat pemasok berdasarkan kelengkapan dokumen halal.

Berikut struktur organisasi Roti Amira beserta perbaikannya yang dipaparkan pada gambar 1 dan gambar 2 di bawah ini.

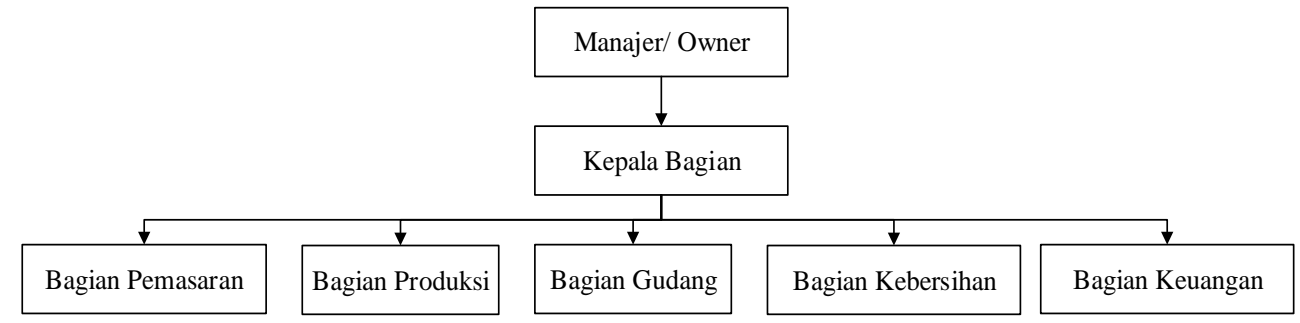

Gambar 1. Struktur Organisasi Roti Amira

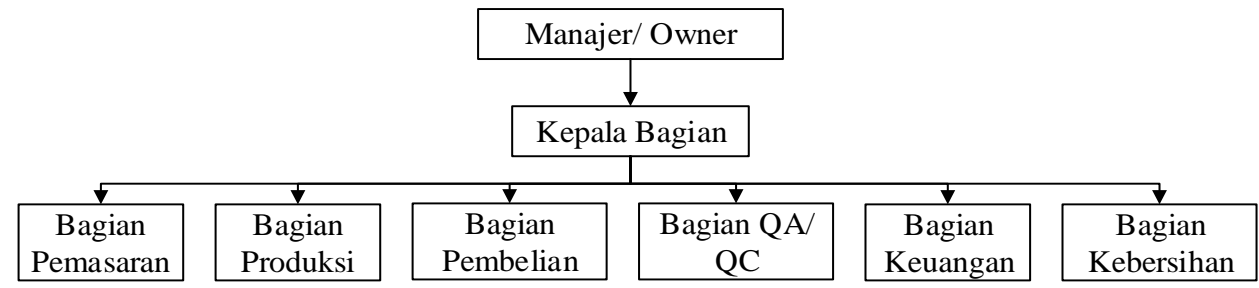

Gambar 2. Perbaikan Struktur Organisasi Roti Amira 


\section{B. Model Value Chain Porter}

Berikut model proses bisnis Roti Amira yang diadopsi dari model value chain Porter yang dipaparkan pada gambar 3 di bawah ini adalah sebagai berikut:

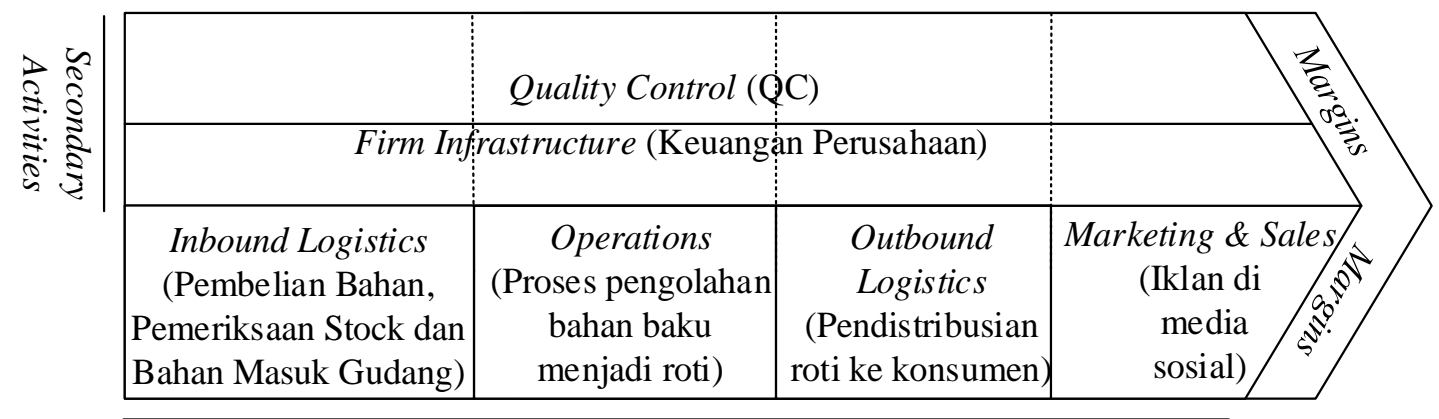

\section{Primary Activities}

Gambar 3. Model Value Chain Porter pada Roti Amira

\section{Primary Activities}

Kegiatan utama berhubungan langsung dengan penciptaan fisik, penjualan, pemeliharaan dan dukungan dari suatu produk atau jasa. Primary activities terdiri dari:

a. Logistik Masuk (Inbound logistics)

Pada aktivitas ini terdapat proses pembelian bahan, pemeriksaan stock dan bahan masuk gudang. Penanggung jawab dari aktivitas ini adalah bagian pembelian.

b. Operasional (Operations)

Pada aktivitas ini terdiri dari: penimbangan bahan baku, pencampuran bahan, penyiapan dan penimbangan ragi, fermentasi pertama, pembentukan, pemotongan, penyiapan dan penimbangan ragi, fermentasi kedua, pemanggangan, pendinginan, pemeriksaan dan packaging. Penanggung jawab dari aktivitas ini adalah bagian produksi dan kebersihan.

c. Logistik Keluar (Outbound Logistics)

Merupakan kegiatan yang diasosiasikan dengan pengumpulan, penyimpanan dan distribusi produk ke pembeli, seperti pergudangan produk jadi, penanganan material, operasi pengiriman, proses pemesanan dan penjadwalan. Pada aktivitas ini terdapat bagian yang bertanggung jawab, yaitu bagian pemasaran dan penjualan. Bagian ini bertugas untuk menjamin produk dijual ke konsumen adalah produk yang halal. Bagian pergudangan juga terlibat dalam penyimpanan produk. Dalam kegiatan ini produk keluar dibagi menjadi dua bagian, yaitu:

1. Distribusi langsung

Penjualan produk didistribusikan secara langsung ke pesanan konsumen.

2. Distribusi ke toko roti Amira

Produk roti dikirim ke toko Roti Amira untuk disimpan dan dijual.

d. Pemasaran dan penjualan (marketing and sales)

Pada marketing and sales, pengiklanan harus sesuai dengan konsep halal. Konten dalam iklan harus berisi sesuatu yang baik atau tidak boleh menggunakan sesuatu dari hal atau nama yang buruk, setan dan haram/ najis. Jika tidak maka, konten iklan harus diganti sesuai dengan syariat Islam. Bagian yang bertanggung jawab adalah bagian pemasaran dan penjualan.

\section{Support Activities}

Kegiatan ini mendukung fungsi utama di atas. Pada aktivitas ini pengelolaan keuangan harus sesuai dengan aktivitas-aktivitas utama agar tidak terjadi kesalahan dan kecurangan dalam pengelolaan keuangan. Jika ada produk baru maka, IKM harus mendaftarkan setiap ada produk baru untuk disertifikasi halal sebelum dipasarkan. Terdapat aktivitas QC sebagai aktivitas kontrol kualitas proses bisnis Roti Amira yang bertanggung jawab adalah bagian QC. Bagian QC selaku bagian auditor sebagai pemantau apakah ada suatu bahan maupun proses yang sesuai dengan kriteria halal.

\subsection{Identifikasi Proses Produksi Beserta Perbaikannya}

Tahap ini dilakukan untuk mengetahui aktivitas masing-masing proses pada setiap divisi di Roti Amira. Dari penjelasan identifikasi proses bisnis Roti Amira yang mengacu model value chain Porter, terdapat empat aktivitas aliran material yaitu: inbound logistics, operations, outbound logistics sampai marketing and sales. Kemudian pada dari kelima aktivitas aliran material terdapat masing-masing proses dibuatlah gambaran yang lebih detail yaitu operations process chart (OPC). Dalam pembuatan OPC ini terdapat OPC saat ini dan OPC perbaikan yang dimana OPC perbaikan merupakan hasil OPC saat ini yang telah diperbaiki dengan pedoman 
SJH. Setelah membuat OPC maka dirancang SOP yang berlaku untuk masing-masing proses bisnis. Berikut penjelasan semua OPC yang ada pada Roti Amira.

\section{A. OPC Pembelian Bahan dan Inbound logistics}

Pada gambar 4 dijelaskan OPC pembelian bahan baku beserta perbaikannya. Proses pembelian bahan baku meliputi pemeriksaan jumlah stock di gudang, pembelian bahan baku, datangnya pesanan, pemeriksaan bahan baku meliputi expired, kualitas serta kuantitas bahan, dan terakhir penyimpanan bahan baku di gudang. OPC pembelian bahan didasarkan pada aktivitas inbound logistics. Di dalam OPC ini terdapat pemeriksaan stock bahan, pembelian dan pemeriksaan bahan serta penyimpanan bahan. Pada gambar 4 terdiri dari dua OPC yaitu OPC saat ini dan OPC perbaikan. OPC yang saat ini berada disebelah kiri gambar dan OPC perbaikan terletak disebelah kanan gambar. Pada OPC inbound logistics terdapat tiga perbaikan yaitu:

1. Perbaikan proses pemeriksaan gudang bahan baku terdapat pemeriksaan kondisi gudang bahan baku apakah sudah steril dari kotoran hewan maupun segala sesuatu dari haram/ najis.

2. Pada perbaikan proses pemeriksaan bahan datang terdapat pemeriksaan yang meliputi expired bahan, expired label halal bahan, label halal, produsen, distributor, kualitas dan kuantitas bahan yang sebelumnya hanya expired, kualitas dan kuantitas bahan. Pemeriksaan bahan berguna untuk mengetahui segala yang berhubungan dengan bahan tersebut apakah kehalalannya sudah sesuai dengan aturan MUI atau belum.

3. Perbaikan proses terakhir yaitu pencatatan pembelian bahan dan inbound logistics. Tujuan dari pembuatan catatan untuk melakukan traceability yang selanjutnya menjadi bahan untuk audit internal.

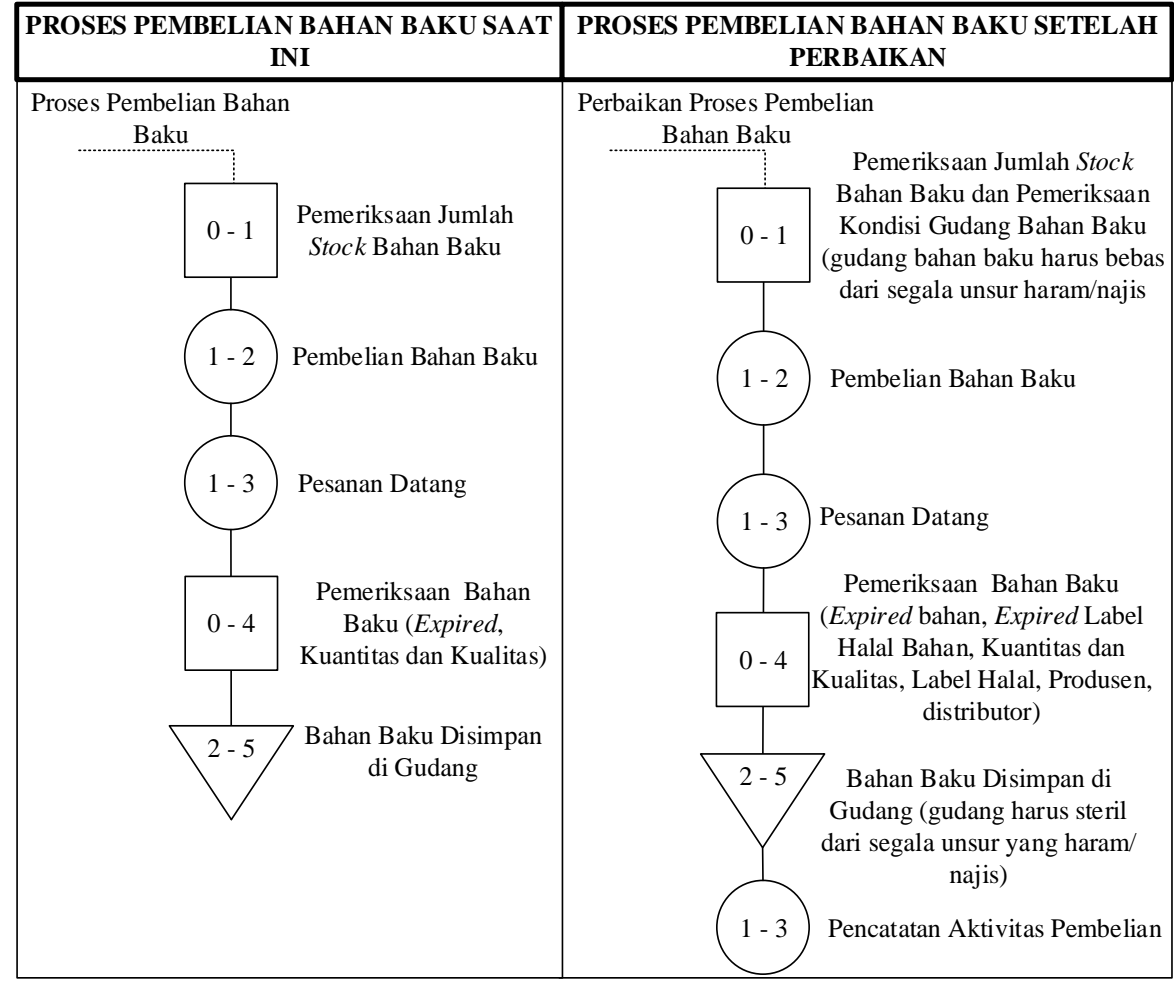

Gambar 4. OPC Inbound Logistics Beserta Perbaikannya

\section{B. OPC Operations (Proses Produksi)}

Pada gambar 5 terdapat OPC proses produksi (operations) yang terdiri dari dua OPC yaitu OPC saat ini dan OPC perbaikan. Produk yang dibuat OPC hanya ada dua, yaitu: roti tawar dan roti semir. Kedua produk ini yang paling laris penjualannya di Roti Amira. Perbedaan roti tawar dengan roti semir hanya pada bahan bakunya. Roti tawar tidak menggunakan telur sedangkan roti semir menggunakan telur. Pada OPC perbaikan terdapat perbaikan yang terdiri dari enam proses, yaitu:

1. Mempersiapkan tahap produksi berupa kebersihan area produksi, gudang bahan baku, peralatan dan karyawan harus steril dari sesuatu haram/ najis. Pada tahap ini bertujuan untuk pengecekan apakah semua komponen dalam proses produksi sudah bersih dari segala haram/ najis. Jika tidak maka, proses tersebut akan menjadi haram/ najis. Untuk pembersihan harus dilakukan sesuai dengan kaidah fiqih.

2. Pembuatan work sheet yang mengacu pada formula dan matriks bahan yang diketahui oleh LPPOM MUI. Pada tahap ini berguna apakah bahan yang digunakan sesuai dengan komposisi maupun daftar 
pada formula baku Roti Amira.

3. Jika ada penambahan bahan baru maka, ada pembuatan titik kritis pada bahan baru tersebut. Tahap ini berguna utnuk menelusuri titik kritis dari bahan baru tersebut.

4. Peralatan dan mesin harus dibuat sticker khusus sebagai penanda produk yang sudah bersertifikat halal dengan yang tidak sebagai lini produksi halal.

5. Pembersihan peralatan dan mesin dari kontaminasi silang antara produk yang bersertifikat halal dengan yang tidak.

6. Pencatatan proses produksi (operations). Tujuan dari pembuatan catatan untuk melakukan traceability operations yang selanjutnya menjadi bahan untuk audit internal.

7. Pada proses fermentasi, adonan roti yang telah dicampur dengan ragi tidak boleh didiamkan lebih dari 1 (satu) hari. Jika tidak, maka adonan tersebut sudah mengandung alkohol dan akan menjadi haram.

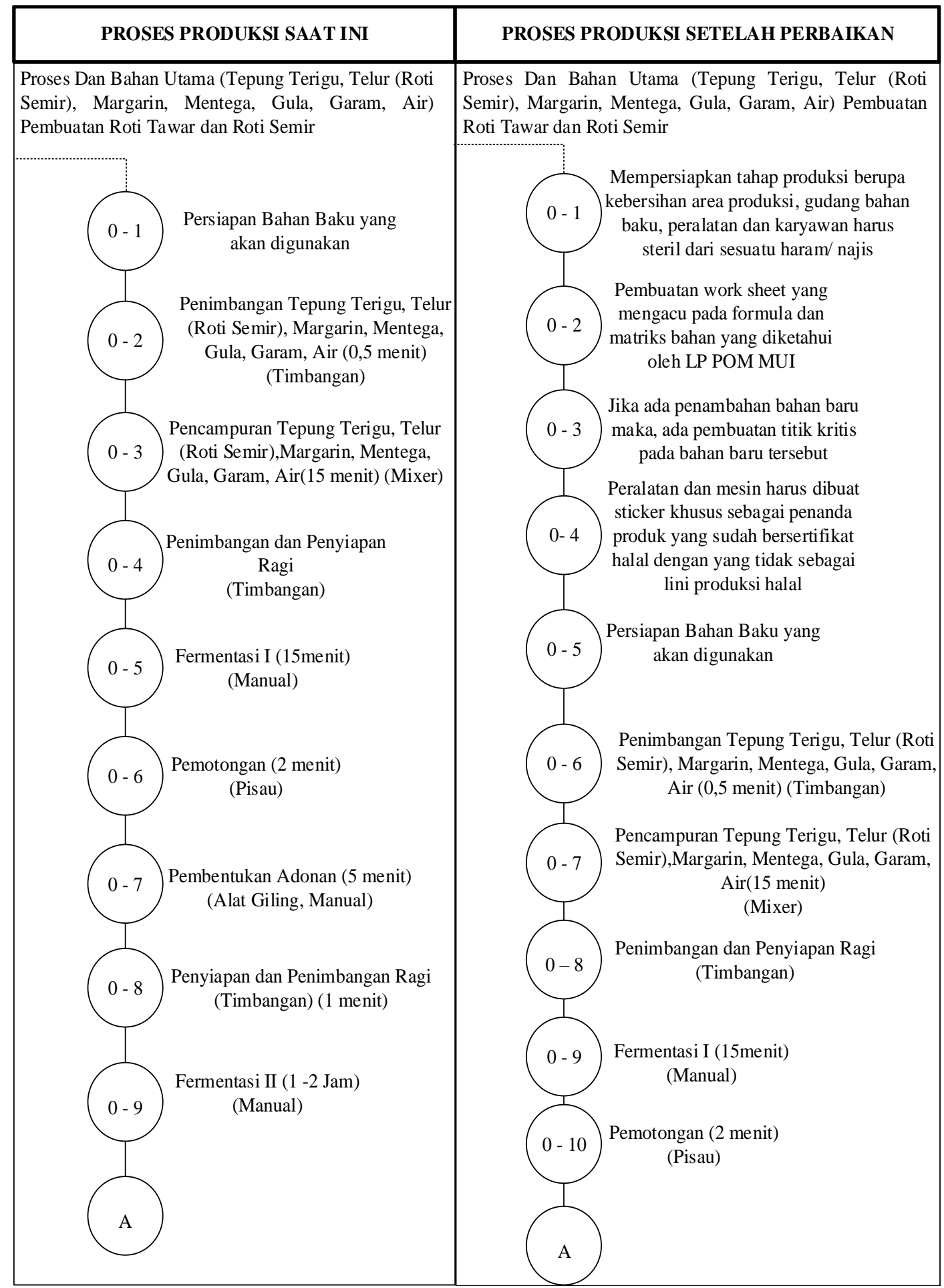

Gambar 5. OPC Proses Produksi (Operations) Beserta Perbaikannya 


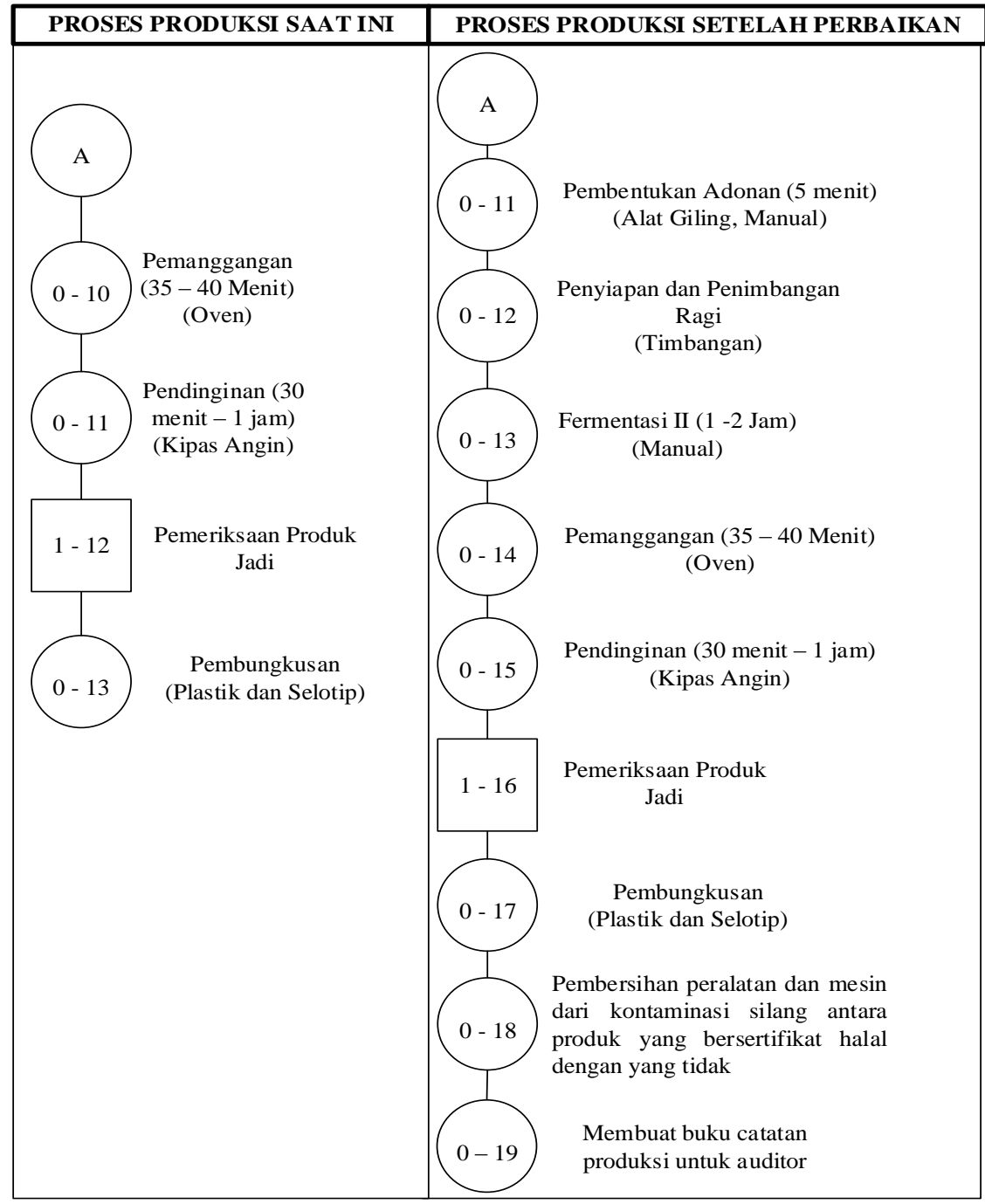

Gambar 5. OPC Proses Produksi (Operations) Beserta Perbaikannya (lanjutan)

\section{OPC Outbound Logistics dan Marketing Sales}

OPC outbound logistics dan marketing sales merupakan alur proses keluarnya logistik produk dan penjualan pada Roti Amira. Pada gambar bagian kiri merupakan OPC saat ini dan untuk bagian kanan untuk OPC perbaikan. Pada OPC perbaikan hanya ditambahkan pada pembuatan catatan penjualan di toko dan penjualan pesanan untuk keperluan audit. Gambar OPC pemasaran dilampirkan pada gambar 6 dan gambar 7. Pada gambar 6 terdapat OPC outbound logistics dan distribusi barang secara langsung ke pesanan. Pada tahap penyoiapan dan pemeriksaan kendaraan yang akan digunakan sebagai distribusi. Kendaraan tersebut harus bersih dari segala haram/najis. Jika tidak maka, kendaraan tersebut harus dibersihkan dahulu sebelum digunakan yang sesuai dengan kaidah fiqih. Pencatatan proses outbound logistics dan penjualan secara langsung. Tujuan dari pembuatan catatan untuk melakukan outbound logistics dan penjualan yang selanjutnya menjadi bahan untuk audit internal.

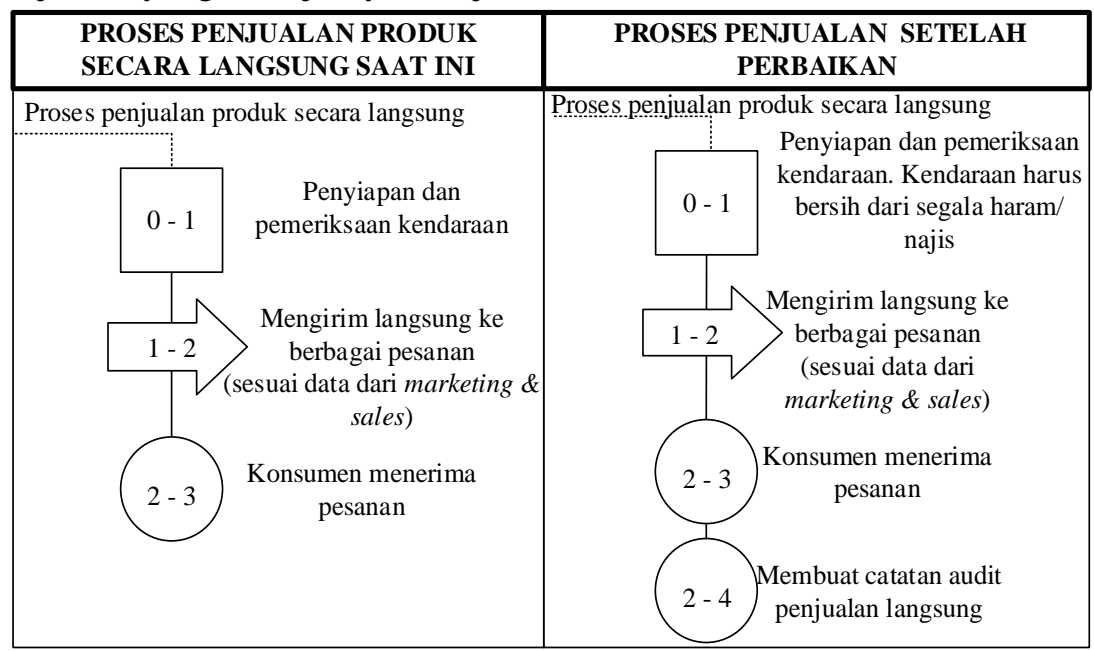

Gambar 6. OPC Outbound Logistics dan Marketing Sales Langsung ke Pesanan Beserta Perbaikannya 
Pada gambar 7 terdapat OPC outbound logistics dan distribusi produk ke toko Roti Amira beserta perbaikannya. Pada perbaikan terdiri dari lima proses, yaitu:

1. Tahap penyiapan dan pemeriksaan kendaraan yang akan digunakan sebagai distribusi. Kendaraan tersebut harus bersih dari segala haram/najis. Jika tidak maka, kendaraan tersebut harus dibersihkan dahulu sebelum digunakan yang sesuai dengan kaidah fiqih.

2. Pada pemeriksaan gudang bahan baku terdapat pemeriksaan kondisi gudang produk apakah sudah steril dari kotoran hewan maupun segala sesuatu dari haram/ najis. Sehingga produk tersebut dapat didsimpan di tempat yang steril dari haram/ najis.

3. Pada pemeriksaan rak display toko, rak display harus sudah steril dari kotoran hewan maupun segala sesuatu dari haram/ najis. Sehingga produk tersebut dapat didsimpan di rak yang steril dari haram/ najis.

4. Produk yang difoto saat diiklankan harus tidak mengandung hal-hal yang bersifat buruk, stean, haram/ najis agar konsumen tahu produk tersebut baik dan halal.

5. Pencatatan proses outbound logistics dan penjualan secara langsung. Tujuan dari pembuatan catatan untuk melakukan outbound logistics dan penjualan yang selanjutnya menjadi bahan untuk audit internal.

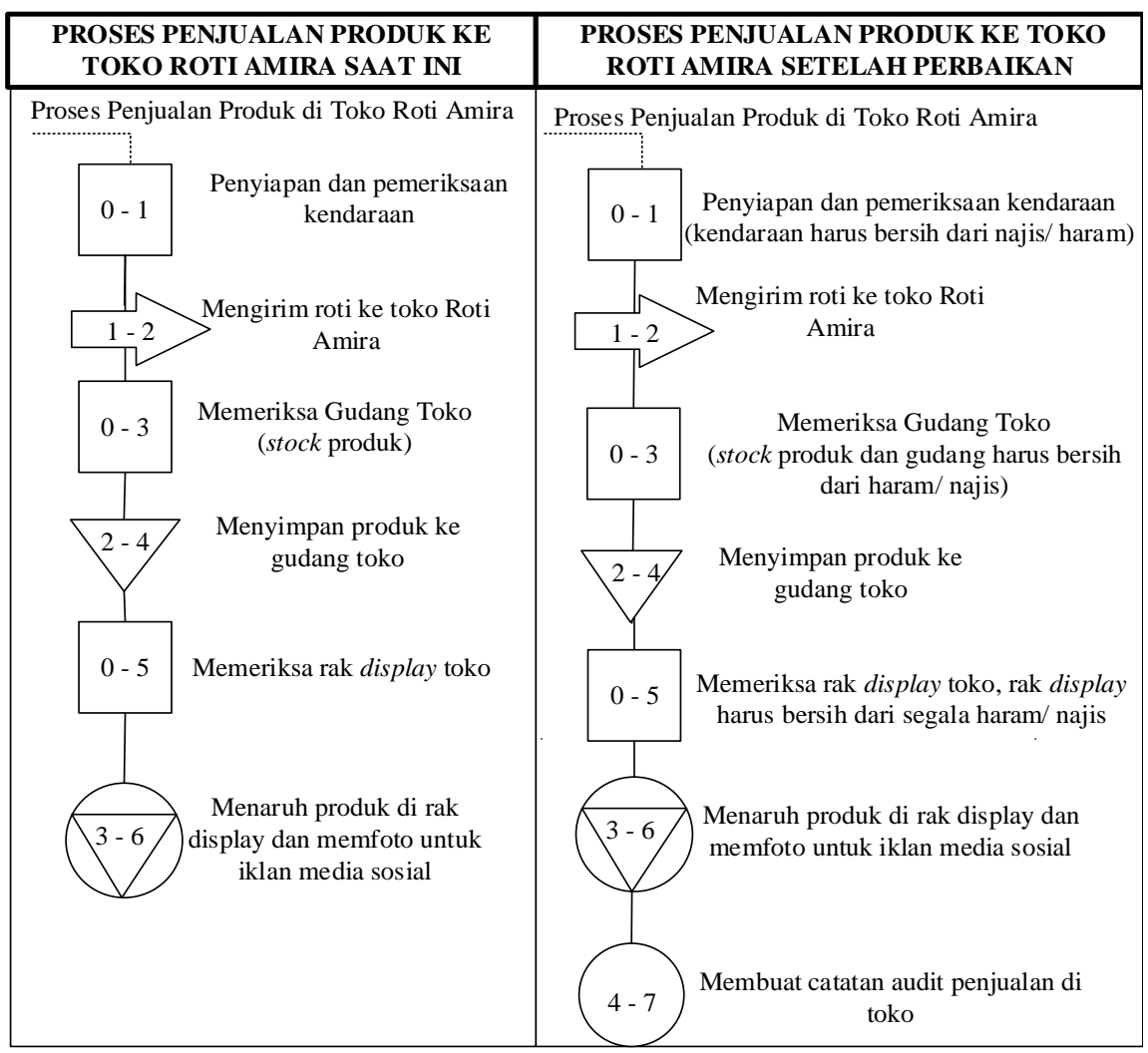

Gambar 7. OPC Outbound Logistics dan Distribusi Produk ke Toko Roti Amira Beserta Perbaikannya

\subsection{Menyusun Matriks Hubungan Dokumen Proses Produksi Halal Dengan Dokumen SJH Untuk Mendapatkan Sertifikat Halal MUI}

Penyusunan matriks hubungan dibuat untuk membuat hubungan kesesuaian antara dokumen proses produksi halal dengan dokumen SJH agar mendapatkan persyaratan dokumentasi sertifikat halal MUI. Pada Tabel 1 terdapat matriks dokumen proses produksi halal dengan dokumen halal MUI. Dokumen proses produksi terdapat sebelas dokumen, yaitu: form perekapan bahan baku, form stock opname, form PPIC, form pemilihan distributor, dokumen permintaan bahan baku dari gudang, Dokumen permintaan penjualan, dokumen formula pembuatan roti, dokumen surat order produksi, dokumen penjualan, dokumen QA/ QC bagian pembelian, dokumen QA/ QC bagian produksi, dokumen QA/ QC bagian penjualan. Pada dokumen pendaftaran halal MUI terdapat sebelas dokumen, yaitu: dokumen kebijakan Halal (standar v), dokumen tim Manajemen Halal (standar vii), dokumen pelatihan dan Edukasi (standar xiii), dokumen Bahan (standar ix), dokumen produk (standar ix), dokumen Fasilitas Produksi (standar ix), dokumen prosedur tertulis Aktivitas Kritis (standar ix), dokumen kemampuan Telusur (standar ix), dokumen prosedur Penanganan Produk yang Tidak Memenuhi Kriteria (standar ix), dokumen audit Internal (standar xv), dokumen kaji Ulang Manajemen (standar xvii).

Dokumen form perekapan bahan baku memiliki hubungan dengan dokumen bahan. Dokumen form stock 
opname memiliki hubungan dengan dokumen bahan. Dokumen form PPIC memiliki hubungan dengan dokumen bahan dan dokumen audit internal. Dokumen form pemilihan distributor memiliki hubungan dengan dokumen bahan dan dokumen kemampuan telusur. Dokumen permintaan bahan baku dari gudang memiliki hubungan dengan dokumen bahan. Dokumen permintaan penjualan memiliki hubungan dengan dokumen produk. Dokumen formula pembuatan roti memiliki hubungan dengan dokumen bahan, dokumen produk, dokumen prosedur tertulis aktivitas kritis, dokumen kemampuan telusur dan dokumen audit internal. Dokumen surat order produksi memiliki hubungan dengan dokumen produk. Dokumen penjualan memiliki hubungan dengan dokumen produk dan dokumen prosedur penanganan produk yang tidak memenuhi kriteria. Dokumen QA/ QC bagian pembelian memiliki hubungan dengan dokumen bahan dan dokumen audit internal. Dokumen QA/ QC bagian produksi memiliki hubungan dengan dokumen bahan, dokumen produk, dokumen fasilitas dan peralatan produksi dan dokumen audit internal. Dokumen QA/ QC bagian penjualan memiliki hubungan dokumen produk, dokumen prosedur penanganan produk yang tidak memenuhi kriteria dan dokumen audit internal.

Pada Tabel 1 ada beberapa dokumen yang belum dipenuhi (belum diberi tanda checklist) yang akan direncanakan pada saat persiapan syarat dokumentasi. Dokumen-dokumen tersebut yaitu dokumen kebijakan halal, dokumen tim manajemen halal, dokumen pelatihan dan edukasi halal dan dokumen kaji ulang manajemem. Dokumen-dokumen tersebut akan dimasukkan didalam aktivitas sekunder dalam value chain model Porter pada gambar 8 di bawah ini.

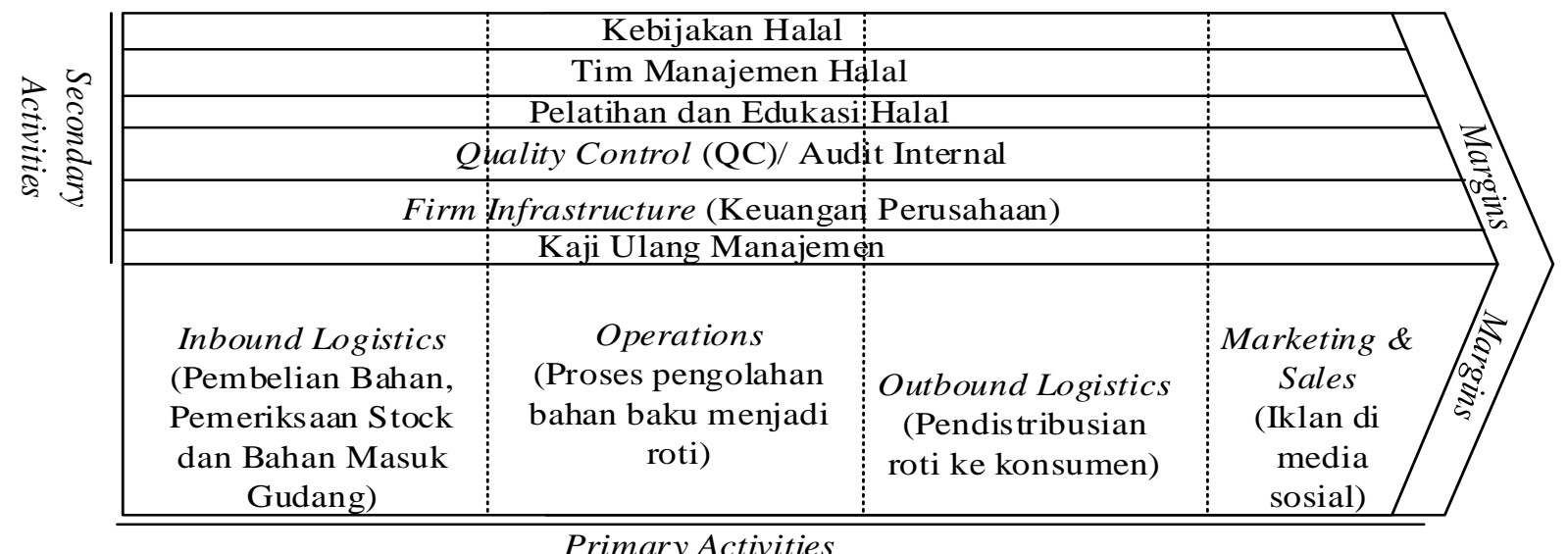

Gambar 8. Model Value Chain Porter Pada Roti Amira Yang Telah Disesuaikan Dengan Matriks Hubungan Dokumen Sistem Produksi Halal Dengan Dokumen Persyaratan Sertifikat Halal MUI. 
Tabel 1. Tabel Matriks Hubungan Dokumen Proses Produksi Halal Dengan Dokumen SJH Untuk Mendapatkan Sertifikat Halal MUI

\begin{tabular}{|c|c|c|c|c|c|c|c|c|c|c|c|c|}
\hline \multirow[b]{2}{*}{ No } & \multirow[b]{2}{*}{ Proses Produksi Halal } & \multicolumn{11}{|c|}{ Dokumen Pendaftaran Halal MUI } \\
\hline & & $\begin{array}{c}\text { Kebijakan } \\
\text { Halal } \\
\text { (standar } \\
\text { v) }\end{array}$ & $\begin{array}{c}\text { Tim } \\
\text { Manajemen } \\
\text { Halal } \\
\text { (standar } \\
\text { vii) }\end{array}$ & $\begin{array}{l}\text { Pelatihan } \\
\text { dan } \\
\text { Edukasi } \\
\text { (standar } \\
\text { xiii) }\end{array}$ & $\begin{array}{l}\text { Bahan } \\
\text { (standar } \\
\text { ix) }\end{array}$ & $\begin{array}{c}\text { Produk } \\
\text { (standar } \\
\text { ix) }\end{array}$ & $\begin{array}{l}\text { Fasilitas } \\
\text { Produksi } \\
\text { (standar } \\
\text { ix) }\end{array}$ & $\begin{array}{c}\text { Prosedur } \\
\text { Tertulis } \\
\text { Aktivitas } \\
\text { Kritis } \\
\text { (standar } \\
\text { ix) }\end{array}$ & $\begin{array}{c}\text { Kemampuan } \\
\text { Telusur } \\
\text { (standar ix) }\end{array}$ & $\begin{array}{c}\text { Prosedur } \\
\text { Penanganan } \\
\text { Produk Yang } \\
\text { Tidak } \\
\text { Memenuhi } \\
\text { Kriteria } \\
\text { (standar ix) } \\
\end{array}$ & $\begin{array}{c}\text { Audit } \\
\text { Internal } \\
\text { (standar } \\
\mathrm{xv})\end{array}$ & $\begin{array}{l}\text { Kaji Ulang } \\
\text { Manajemen } \\
\text { (standar } \\
\text { xvii) }\end{array}$ \\
\hline 1 & $\begin{array}{lll}\text { Form Perekapan Bahan } \\
\text { Baku }\end{array}$ & & & & V & & & & & & & \\
\hline 2 & Form stock opname & & & & $\mathrm{V}$ & & & & & & & \\
\hline 3 & Form PPIC & & & & $\mathrm{V}$ & & & & & & $\mathrm{V}$ & \\
\hline 4 & $\begin{array}{ll}\begin{array}{l}\text { Form } \\
\text { distributor }\end{array} & \text { pemilihan } \\
\end{array}$ & & & & V & & & & V & & & \\
\hline 5 & $\begin{array}{l}\text { Dokumen permintaan } \\
\text { bahan baku dari gudang }\end{array}$ & & & & V & & & & & & & \\
\hline 6 & $\begin{array}{ll}\text { Dokumen permintaan } \\
\text { penjualan }\end{array}$ & & & & & $\mathrm{V}$ & & & & & & \\
\hline 7 & $\begin{array}{ll}\begin{array}{l}\text { Dokumen } \\
\text { pembuatan roti }\end{array} & \text { formula } \\
\end{array}$ & & & & V & $\mathrm{V}$ & & $\mathrm{V}$ & V & & V & \\
\hline 8 & $\begin{array}{lll}\begin{array}{l}\text { Dokumen } \\
\text { produksi }\end{array} & \text { surat } & \text { order } \\
\end{array}$ & & & & & V & & & & & & \\
\hline 9 & Dokumen penjualan & & & & & $\mathrm{V}$ & & & & $\mathrm{V}$ & & \\
\hline 10 & $\begin{array}{l}\text { Dokumen QA/ QC bagian } \\
\text { pembelian }\end{array}$ & & & & V & & & & & & V & \\
\hline 11 & $\begin{array}{l}\text { Dokumen QA/ QC bagian } \\
\text { produksi }\end{array}$ & & & & V & $\mathrm{V}$ & $\mathrm{V}$ & $\mathrm{V}$ & & & V & \\
\hline 12 & $\begin{array}{l}\text { Dokumen QA/ QC bagian } \\
\text { distribusi dan penjualan }\end{array}$ & & & & & V & & & & $\mathrm{V}$ & V & \\
\hline
\end{tabular}




\section{Simpulan}

Kesimpulan yang dihasilkan dari penelitian ini adalah sebagai berikut:

1. Dalam perbaikan proses produksi halal pada Roti Amira terdapat empat perbaikan yang terdiri dari: perbaikan proses bisnis, perbaikan proses produksi, perbaikan SOP halal dan membuat matriks hubungan dokumen proses produksi halal dengan dokumen persyaratan halal MUI.

2. Pada proses bisnis dapat dilakukan perbaikan struktur organisasi halal, dengan penambahan struktur anggota yaitu: bagian QA/ QC dan bagian PPIC. Pada perbaikan alur proses bisnis Roti Amira dilakukan dengan standar MUI.

3. Kesebelas dokumen SJH Roti Amira disusun dari model matriks hubungan dokumen proses produksi halal dengan dokumen persyaratan halal MUI. Matriks tersebut menggambarkan tujuh dokumen proses produksi halal dengan dokumen persyaratan halal MUI. Dokumen tersebut terdiri dari: dokumen bahan, dokumen produk, dokumen fasilitas produksi, dokumen prosedur tertulis aktivitas kritis, dokumen kemampuan telusur, dokumen prosedur penanganan produk yang tidak memenuhi kriteria dan dokumen audit internal. Dokumen yang belum disediakan dari proses produksi harus mengadopsi dokumen halal MUI. Adapun dokumen tersebut antara lain sebagai berikut: dokumen kebijakan halal, dokumen tim manajemen halal, dokumen pelatihan dan edukasi, serta dokumen kaji ulang manajemen.

\section{Daftar Pustaka}

Denny, W., (2018). Contoh Isian Manual Standar Jaminan Halal (SJH) Tahun. DOI: 10.13140/ RG.2.2.18589.36321.

Majelis Ulama Indonesia (MUI). (2008). Panduan Umum Sistem Jaminan Halal LPPOM MUI.

Majelis Ulama Indonesia (MUI). (2010). Penggunaan Mikroba dan Produk Mikrobial Dalam Produk Pangan.

Majelis Ulama Indonesia (MUI). (2013). Daftar Bahan Tidak Kritis LPPOM MUI.

Rusda, I., \& Enstien B. (2016). Perancangan Standard Operating Procedure (SOP) Proses Pembelian Bahan Baku, Proses Produksi dan Pengemasan pada Industri Jasa Boga (Studi Kasus pada PT. KSM Catering \& Bakery Batam). Jurnal Akuntansi, Ekonomi dan Manajemen Bisnis, Vol. 4 No. 2, .186-193.

Undang-Undang Republik Indonesia Nomor 33 Tahun 2014 Tentang Jaminan Produk Halal. Majelis Ulama Indonesia Diakses pada September 2018, dari http://simbi.kemenag.go.id/halal/assets/collections/ newsletter/files/55642ca917160.pdf 